\title{
Challenges of Getting Lexical Equivalents in Interpreting Religious messages: Case study of Public Religious Meetings in Bondo Town-Kenya
}

\author{
Silas Odhiambo Owala \\ School of Humanities and Social Sciences \\ Bondo University College \\ P.O Box 210-40601 \\ Bondo, Kenya \\ Tel: 254-725-872-424Ｅ-mail: oowala2000@yahoo.com \\ Juliet Akinyi Jagero (Corresponding author) \\ School of Humanities and Social Sciences \\ Bondo University College \\ P.O Box 210-40601 \\ Bondo, Kenya \\ Tel: 254-722-970-690Ｅ-mail: jageroakinyi@yahoo.com
}

Received: Nov. 26, 2012 Accepted: December 16, 2012 Published: February 28, 2013

doi:10.5296/ijl.v5i1.3300ＵRL: http://dx.doi.org/10.5296/ijl.v5i1.3300

\begin{abstract}
Interpretation plays an important role in religious meetings where those in the audience speak different languages. However some interpreters face serious challenges in their attempt to interpret the messages from one language to the other. This paper discusses some difficulties of lexical nature in interpreting religious messages in Bondo town in Kenya. The main objective of the study was to establish challenges in translation during religious meetings where English and Luo languages were used. Data was collected by taping the messages during the meetings. These were then transcribed and analyzed to establish whether the lexical items in the interpreted message gave the accurate message that the orator intended to
\end{abstract}




\section{Macrothink}

International Journal of Linguistics

ISSN 1948-5425 2013, Vol. 5, No. 1

put across to the audience. The analysis showed that a number of lexical items used did not give the accurate message the orator intended to pass to the audience. This distorted the message in a number of cases.

Keywords: Interpretation, Lexical items, Source language, Target language 


\section{Introduction}

In recent years there has been an increase in population in Bondo town. This is as a result of increased business activities and establishment of educational institutions including Bondo Teachers College and Bondo University College. A significant part of this population does not speak Luo language which is the language of the local people. This has posed a major challenge to religious leaders who have to find ways of ensuring that those who attend their church services but do not understand the local language are catered for. Most religious leaders have resorted to having an interpreter during religious meetings in order to assist them make it possible for everybody in their congregations to understand the message.

Interpretation plays an important role in many fields in many parts of the world. This is due to the fact that there have been a lot of changes in peoples lifestyles due to communication technology, better methods of travel and rural urban migration due to economic and other reasons. The resultant interaction has made it necessary for people speaking different languages to work together in various ways. One of the areas of interaction is the area of religion and worship. This situation is common in many towns in Kenya where there are many people of mixed linguistic backgrounds-Kenya have a total of 42 tribes each speaking a different language. Religious leaders in Kenya therefore turn to on spot interpretation as the best available way of communicating with their audiences.

Unlike translation where there is time for the translator to carefully examine text, these interpreters are expected to present the message from one language to another on the spot. This bestows a heavy responsibility on the interpreter just like the speaker. If there is any shortcoming in the message, he/she takes the blame. He/she is an important link between the orator and his/her audience. If the interpretation collapses the orator too fails in communicating the desired message to the audience.

\section{Literature Review}

\subsection{Interpretation}

Interpretation is closely related to translation. Cremona and Mallia (2001) who are experienced interpreters in international meetings explain the main difference between translators and interpreters. According to their observation a translator basically works alone with paper and text. He/she recreates the text anew by becoming its second author. The interpreter on the other hand does not work alone. He/she works with the orator who in some cases explains his point and his ideas without giving the interpreter time to think about the explanations or the most appropriate equivalents. It is worth noting that the interpreter has an audience listening to him and to the orator. The time difference between what the speaker says and expectation of the audience from the interpreter is often very short. This can put pressure on an interpreter and lead to haphazard choice of lexical items to avoid keeping the audience waiting.

Nida (1964) Explains that translation is to present in the target language the message of the source language as closely as possible both in meaning and style. Interpretation is also based on this principle. The difference is that it is done on the spot while translation is done on text 
but the idea of transferring meaning remains the same. It is important to note however that it is very difficult to get two languages that are exactly the same. This can pose very serious challenges to an interpreter especially if the two languages involved are of different cultural backgrounds.

\subsubsection{Approaches to Interpretation}

Interpretation like translation can be direct or free. In most parts of the world it is rare to come across direct translation unless what is being translated are proper nouns. This is largely because linguistic differences in the various languages do not allow direct translation and more particularly so if the two languages involved come from different language families. The examples given in this paper are from different language families- English and Luo.

Mwansoko (1996) observes that word for word or direct translation is unsuitable. He contends that this kind of translation puts emphasis on the basic meanings of words while ignoring the context of usage. In many cases it lacks clarity in expressing the intended meaning. In the case of on spot interpretation an interpreter is expected to make quick judgment of the intention of the orator rather than concentrate on the words. This can be difficult in some occasions depending on the linguistic capability of the interpreter, the speed of the orator, cultural considerations that make it difficult to get equivalents and even communication barriers especially if loudspeakers are in use in an open air situation. Because of the limited time the interpreter has, the temptation to concentrate on words rather than the message of the interpreter is often great. This can lead to breakdown in communication between the orator and the audience.

\subsubsection{Linguistic Aspects of Interpretation}

Interpretation is a process of transferring meaning from one language to another. Linguistics is about language as it manifests itself at different levels e.g. phonological, morphological, syntactical and semantic. All languages of the world can be analyzed at those levels. This paper attempts to establish how choice of lexical items during interpretation can affect transfer of meaning from source language to target language.

Nida (2002) stresses the importance of functional equivalents in translation. Interpretation then must be based on meaning rather than loyalty to words that can cause problems in meaning. People's interest is in meaning rather than words. While it is easier to translate word for word, these words may not necessarily convey the intended meaning. This is because words carry different meanings depending on the context. The issue of context is important in this study because in Luo language a word can have different meanings depending on the context in which it is used. Lack of care in interpreting from Luo to other languages could lead to a problem of collocation thereby leading to absurdities.

Shi (2004) observes that in translation or interpretation there is need for accommodation in the target language. In accommodation changes are made so that the target text is in line with the spirit of the original. Translation therefore is not simply a linguistic change between languages but rather an accommodation at cultural, political and even aesthetic levels. 
Accommodation is a must to preserve the value of the source message. There has been among interpreters an argument on whether to put emphasis on faithfulness to words or aesthetics. This comes from two contrasting theories of where to put the emphasis i.e. source message, against target message. For a long time the latter has been more popular. However in recent years there has been a shift towards the latter. In religions meetings there is need for the interpreter to ensure that the recipient of the message benefit from his interpretation rather than dwelling on merely translating words from the source language. It is agreed among many linguists that there are linguistic and cultural reasons that make some words untranslatable. This makes it necessary to pursue accommodation rather than translating word for word. An interpreter then is expected to give explanations that will enable the audience get concepts as closely as possible. It is our contention that interpretation which puts emphasis on the target message rather than source message was much better. In our opinion, apart from presenting what the orator was saying, it was necessary to ensure the target audience got the message in an intelligible form. According to Cohen (1985) the fact that concepts and words are not equivalent is shown by the fact that one word can have more than one meaning in the same language. An example is the word 'kendo' in Luo which can mean again, marry and fireplace depending on the context in which it is used. Each of these meanings represents a different concept. Mistranslations happen when in the source language one word represents several concepts while in the target language each of the same concepts is symbolized by a different word. To be accurate, the translator has to identify the concept and the referent that the word in the source language represents. If the interpreter fails to distinguish all the different concepts that the word in the source language stands for, the interpreter may select a word in the target language that represents the wrong referent.

In Michelangelo's sculpture of Moses, the Latin translator of the bible encountered the phrase which in Hebrew means "and rays glowed from Moses face" - in Hebrew rays and horns are referred to by the same word "Karnayim" the translator selected the Latin word for horns and mistranslated the sentence as "and horns grew on Moses heads". This is an example of one of the problems that an interpreter has to deal with considering that an interpreter has even less time compared to a translator.

\section{Theoretical Framework}

This research was guided by Nida's theory of translation 1964. One of the major assertions of this theory is that language is a product of culture and that almost all problems of translation are caused by environmental and cultural factors related to any pair of languages. Culture plays an important role in language. This can be a problem for any two people who speak different languages and also come from different cultures and environments. The process of translation or interpretation where two cultures are involved often causes a number of issues.

Some of these are: -

- Literal translation.

- Avoidance of certain words.

- Inability to get equivalents due to cultural and environmental differences in the two 
languages.

This research assessed problems in interpreted messages that arose as a result of the interpreter using an inappropriate lexical item. This problem of choice on some occasions occurred because of cultural and environmental differences surrounding Luo and English. English differs with Luo in its environmental set up, religious beliefs, socially and even structurally. These differences caused a problem in obtaining equivalents or words that could describe a similar concept in the target language. Seasons in Luo and English for example are different. English has Summer, Autumn, Winter and Spring while Luo has only two seasons Chwiri and Opon which basically mean long and short rainy season. These kinds of differences pose quite a challenge for an interpreter. Structures of different languages can cause difficulties too during interpretation. Sometimes it forces an interpreter to use a phrase in the target language where the source language presents the concept in only one word. The concept of 'dry cow' for example when translated directly into Luo does not have the same meaning. A Luo speaker would understand "A cow that has stopped producing milk". The explanation rather than the translation is what makes sense. During interpretation, the orator may use few words and move on without considering that sometimes longer explanations of the concepts are required in the target language. If the orator does not give the interpreter enough time this can lead to loss of meaning in the target language. Nidas explanation of the relationship between culture and language is important in analysis of language as presented by the orator and interpreter at both lexical and syntactical levels.

\section{Methodology}

\subsection{Sampling Procedure}

Speeches were recorded during religious public meetings where there was interpretation from English to Luo. This recording was done in six separate meetings. All the meetings were near the bus park within Bondo Town. Orators during all the six meetings were different people same as their interpreters. This was done to enable the researcher asses the performance of various interpreters and also to draw an objective conclusion.

\subsection{Data Collection Tools}

Data was collected using a tape recorder which was used to tape the speeches. A questionnaire was used to gauge the opinion of the audience about the interpretation. A table was used to record the responses given by the audience about the interpretation.

\subsection{Data Analysis}

The Qualitative and Quantitative approaches to data analysis were used in this study. The Data were initially described and summarized using descriptive statistics (Mugenda et al 1999). Consequently, the tape-recorded conversations were transcribed on paper. The extracts from the transcribed text were studied to identify the errors in the interpretation. 


\section{Findings and Discussions}

\subsection{Responses from the Audience}

Five people from the audience were interviewed after the meetings. The purpose was to find out their opinion of the interpretation. The record of their responses is presented in the table below.

Table 1. Responses from audience

\begin{tabular}{|c|c|c|c|c|c|}
\hline \multirow[t]{2}{*}{ QUESTION } & \multicolumn{4}{|c|}{ Response } & \multirow[b]{2}{*}{ Total } \\
\hline & Yes & Percentage & No & Percentage & \\
\hline Interpreter did well & 10 & $33.3 \%$ & 20 & $66.7 \%$ & $100 \%$ \\
\hline $\begin{array}{l}\text { Orator gave } \\
\text { interpreter enough } \\
\text { time }\end{array}$ & 5 & $16.7 \%$ & 25 & $83.3 \%$ & $100 \%$ \\
\hline $\begin{array}{l}\text { The interpretation } \\
\text { could be improved }\end{array}$ & 28 & $93.3 \%$ & 2 & $6.7 \%$ & $100 \%$ \\
\hline
\end{tabular}

The responses are an indicator of some shortcoming in the interpretation. 33\% said the interpreter did a good job. However $67 \%$ did indicate that the interpretation may not have been done well. This means that many people who attended the meetings were of the opinion that the interpretation was poor. If that percentage felt that it was not good, then there must have been problems with the interpretation. It is significant that among those who felt the interpretation was good when asked if the interpretation could be improved, they responded in the affirmative. This means their response to the first question may not have expressed exactly what they thought about the interpretation.

Only $16.7 \%$ said the orator gave the interpreter enough time. Time here refers to the interval between interpretation and the orator beginning of the next sentence. Some of the orators did not give enough time to the interpreter to complete what they had said earlier before starting their next sentence. This meant that the interpreter had to listen while at the same time translating the orators' earlier words. $83.3 \%$ felt the interval was not enough. This could have been one of the reasons for the poor performance by the interpreter. $93 \%$ felt there was need for improvement in the interpretation; their judgment then was that the interpretation had problems. Those interviewed had enough mastery of the both languages; English and Luo. They were selected because those with mastery of only one language would not give an objective assessment of the interpretation.

We also wanted to asses if the orator's message in the source language was understood as it were in the target language. We took the transcriptions and gave to people who never attended the meetings. We gave them the interpreted message and asked their opinion on whether it was clear. $90 \%$ of the respondents said they could not clearly get the meaning. This was an indicator that those in the audience who only understood the target language may not have got the message as intended by the orator. When the original message was given to the same respondents, they said they could clearly understand the message. This clearly 
demonstrated that interpreted speeches were less clear. This was as a result of problems in the interpreted version of the speeches because the interpretation was not done well due to lexical problems that we were able to identify.

\subsection{Lexical Problems in the Interpretation}

These arose in various ways. In some cases, the interpreter used a word that caused semantic ambiguity. In such instances logic was lost. In some cases, the interpreter left some words untranslated. We investigated if the ignored words had equivalents in the target language. If we found equivalents, our verdict was that this was the interpreter's failure. However, where equivalents were not found, we assumed this was as a result of the differences in the two languages. We considered that it is sometimes difficult to explain a concept in a target language despite its presence in the source language. This is one of the concerns of Sapir Whorf hypothesis. This difficulty occurs as a result of the differences in world view of any two languages. Despite this, any two languages have a relationship although not at all levels. It is this minimal relationship that makes it possible for one language to be translated to another. Some of the difficulties that arose in the interpretations studied were as a result of these differences in world view. The areas where difficulties occurred were studied to explain how they occurred. One of the discoveries was that choosing a wrong lexical item could be as bad as ignoring some words during interpretation. The following examples illustrate our point.

Orator: Was I born for this? Was I born for this? (Eng.)

Interpreter: Ne onywola ne gin? (Luo)

In this extract there is a misunderstanding between the orator and the interpreter. The interpreter said "was I born for them" while the orator was asking a rhetoric question "was I born for this "work"? Quotation added by the author. The interpreter thought the orator had said 'these' rather than 'this' the problem here was phonological which resulted in the orator getting the wrong word. This altered the meaning of the orator's intention completely.

Orator: You don't know the excitements that I experience. (Eng)

Interpreter: Ok ung'eyo mor ma asiko aneno. (Luo)

The words used for excitement and experience do not adequately describe those concepts. For excitement the interpreter used the word 'mor' which means happiness. There is an equivalent 'ilo' in Luo which the interpreter did not use but which was the most accurate description of what the orator said. The use of the word 'aneno' was inappropriate. It simply means 'see'. The Luo word 'awinjo' which means 'felt' would have been more appropriate for the word experience. The interpreter used words which did not present the orators message correctly.

Orator: He was waiting to see my passport and my visa. (Eng)

Interpreter: Kendo ne orito neno paspot na, gi visa mara bende. (Luo)

Here the interpreter used the words passport and visa without translating them. Luo language 
has no equivalents for passport and visa. However there was need for the interpreter to explain the meaning of those documents. This was not done. If there were people in that audience who did not understand any English at all, then they would not know what was said.

Orator: The spirit of the Living God. (Eng)

Interpreter: Roho mar Nyasaye. (Luo)

In this interpretation the interpreter used the word 'Roho' which is actually a Kiswahili word. Those in the audience would understand it because it is commonly used in religion discourse in Kenya. The interpreter however ignored the word 'living'. This is an important attribute of God which the orator wanted to put across. The Luo word 'mangima' could be used by the interpreter he however did not find this word.

Orator: I have a passport to the next world. (Eng)

Interpreter: Antie gi otiko mar piny machielo. (Luo)

The interpreter has used the word 'otiko' to mean passport. The word 'otiko' is an adaptation of the English word Ticket. The use of this word is not appropriate for two reasons. First, he had already used paspot in an earlier interpretation. It would have been wiser to continue using the same word for the same concept. Changing the word could easily confuse the audience. Secondly, the concepts of ticket and passport are different. The fact that a ticket is paid for negated the message of the orator who was trying to explain that people do not have to pay anything in order to inherit the Kingdom of God.

Orator: It was an experience. (Eng)

Interpreter: Ne en gima atimo. (Luo)

This interpretation means " it is what I had done ".

This is not what the orator said. The orator was trying to narrate the experience of meeting his wife's grandmother. The interpreter did not get an equivalent nor explain the word in context. In Luo if he said 'ne en gima akale' meaning 'it's what I went through', this would have been a more appropriate interpretation.

Orator: I thought it was my fault and I knew that right away. (Eng)

Interpreter: Ne aparo ni en wachna, ne ang'eyo mana kamano. (Luo)

Space created here

The meaning of the orators words did not come out clearly in the interpretation. The interpretor ignored the word 'fault' thus missing out the idea of him being blamed by the wifes grandmother for changing her grand daughter's denomination.

Space created here

Orator: He was going to hang on the cross. (Eng)

Interpreter: Ne ong'eyo ni odhi dere e bao. (Luo)

The word used for 'hang' in this translation actually means 'commiting suicide' ! This does not bring out the biblical teaching of crucifixion of Jesus for sins of man. The interpreter was trying to literarly translate the word 'hang' from American English who use it instead of 
'crucified'. His lack of knowledge of the American English led him to give an incorrect interpretation.

Orator: It's a character of tenderness, kindness, humility, meekness and longsuffering. Interpreter: En ranyis mar ng'wono, mohore, bedo ratiro, kendo bedo maonge mibadhi.

Many words used by the orator were not translated. Only 'kindness' and 'humility' were translated correctly. The other words were either ignored or incorrectly interpreted. The word character was interpreted as 'ranyis' The word 'ranyis' means 'example'. It cannot therefore mean character. In Luo language the word 'tim' would have been more appropriate. The word 'tenderness' was not translated despite having an equivalent in Luo - 'muolo'. However, the word longsuffering poses quite a challenge as used in the bible; it is difficult to get a similar concept in Luo. The difficultly illustrates the difference in world views of the two languages. This makes the message from the source language to be incorrectly presented in the target language. The lack of equivalents made the interpreter use words that have different meanings from the intended concepts. The word 'mibadhi' means corruption and the words 'bedo ratiro' means honest. Those in the audience who only understand Luo therefore got a completely different idea from that intended by the orator.

Orator: Why do I do what I do? Answer Because of Jesus. (Eng)

Interpreter: En ango momiyo atimo gima atimo? Ang'sa Nikech Yesu. (Luo)

In this section there are two problems. First, the word answer was not translated, instead the word answer was borrowed and adapted to the target language. This was done despite the fact that there is an equivalent, "duoko" which could be used. Secondly, this kind of borrowing depends on the ability of the audience to understand the source language unless the words are onomatopoeic. If there are people in the audience who do not understand the source language, then they would not be able to understand the message of the orator.

Orator: Jesus said, I am the true vine. (Eng)

Interpreter: Yesu ne owacho ni an e mzabibu. (Luo)

In the interpretation the word 'true' was ignored. The word true was very important in the orators message. In the Christian faith, ignoring the word 'true' waters down the stress on the role of Jesus. The word 'vine' was interpreted as 'mzabibu'. This is not a Luo word but rather Kiswahili word. It was not possible to get a Luo word because vines are not grown in the areas where Luo is spoken. This word has however been used many times in this region and the audience understood what it means. However, it was necessary for the interpreter to explain. It was difficult to give the explanation because of the interval. Religious public meetings are quite fast paced and this greatly reduces the time available for the interpreter to make any meaningful expalnations thereby creating even more problems in the interpreted messages.

Orator: You are the branches of Jesus. (Eng)

Interpreter: Un e bede yath. (Luo)

The interpreter ommited 'Jesus' and instead used 'yath' which means tree. The interpreter 
appeared to find it difficult to say branches of Jesus since Jesus is not a tree; yet the statement used by the orator was metaphorical. In the interpretation, this metaphor is lost. When figurative expressions are ignored in interpretations it makes the resultant speech in the target language less interesting.

Orator: No matter what wiser, the blood of Jesus flows through us. (Eng)

Interpreter: Remb Yesu mol kuomwa. (Luo)

The interpreter ignored the words no 'matter what wiser'. These words exist in Luo. It is not clear why the interpreter chose to ignore them yet they were very important. That substantially changed the orator's message which was meant to let the audience know that whatever the status of the person, the blood of Jesus flows through them. The target audience got a different message.

Orator: God who changes situations. (Eng)

Interpreter: Nyasaye maloko paro. (Luo)

The word used for "situations' by the interpreter "paro" actually means "thought". A word exists in Luo-Lokruok which would have been more appropriate.

Orator: He prunes the branches. (Eng)

Interpreter: Odoyo. (Luo)

The word 'odoyo' used by the interpreter means 'weed' literarily meaning removing the weeds. This is a completely different concept from pruning. The word 'luero' in Luo would have been more appropriate. It means prune. The interpreter did not however use this word.

\section{Conclusion}

This research has demonstrated that there were problems with interpreted messages during religious meetings in Bondo. The problems mainly occurred as a result of difficulty in obtaining the appropriate lexical equivalents to represent a concept from the source language to the target language in the two languages studied. This was mainly due to differences in cultures of the two languages caused by environmental differences between the two languages. As already explained above Nida (1964) asserts that the differences in any two languages are as a result of the differences in their cultures. The environment is part of this culture. Lexical items that are found in a language are therefore pegged on its environment. The problems experienced in interpreted messages during religious meetings in Bondo were as a result of environmental diversities that made it difficult to get appropriate lexical equivalents in the target language-Luo. This led to distortion of the orator's message in some cases.

\section{References}

Cremona, V., \& Mallia, H. (2004). Language and diplomacy interpretation and diplomacy. Malta: Diplo projects

Fram-Cohen, M. (1985). Reality language translation. What makes translation possible. American Translators Association conference. Miami. Retrieved from 
http//enlightenment.supersaturated.com.

Mugenda, O. M., \& Mugenda, A.G. (1999). Research method: Quantitative and qualitative approaches. Nairobi: Centre for Technology.

Mwansoko, H. J. M. (1996). Kitangulizi cha tafsiri: Nadharia na mbinu Dar es Salaam TUKI.

Neff, D. (2002, October 07). Meaningful translation Christianity Today, 46(11).

Nida, E. A. (1964). Towards a science of translating. Leben. E.J Brill.

Nida, E. A. (1969) The theory and practice of translation. New York. United Bible Societies

Shi. A. (2004). Accommodation in translation. Translation Journal, 8(3). Retrieved from http://www.tranlationjournal.net/journal/29accm.htm 